A Good Example of MToral Imbecility.

Unlike many a recidivist, Jane has, I believe, never excused her repeated offences by alleging they were the result of the severity of the initial sentences of imprisonment passed upon her; her early sentences, in fact, were conspicuous for their moderation. Her career is not the result of an indolent nature drifting more or less passively into crime as the easiest way of getting a living, nor is it the outcome of the gambler's prompting, which so frequently causes crime; it is the inevitable result of active criminal desires constantly urging and seeking opportunity for the commission of crime, and constitutes, I believe, a good example of moral imbecility. Jane is a "luckless pot marr'd in the making," and well might she say :-

They sneer at me for leaning all awry;

What! did the Hand then of the Potter shake?"

She complies with the four requirements of moral imbecility as laid down in the Mental Deficiency Act, 1913. "A person who from an early age displays some permanent mental defect coupled with strong vicious or criminal propensities on which punishment has had little or no deterrent effect." From childhood she has displayed, as shown in this narrative, strong criminal and also vicious propensities upon which repeated punishment has had no deterrent effect, and it can be safely predicted never will have any deterrent effect. Her delinquencies have lasted for a period approaching 25 years, and no one would hesitate to say they will persist. If we accept Mercier's doctrine that crime is due to temptation or opportunity, the environmental factor or stress, acting upon the inherent or constitutional factor, temperament, then Jane's incorrigibility appears evident. The constitutional factor is chiefly at fault, the environmental factor being insufficient to cause habitual crime in a person of normal or approximately normal temperament, and there can now be no prospect of change in her inherent mental constitution. That she is a woman of some talent, ability, and cleverness cannot be gainsaid, but she lacks discretion and fails in the higher mental level-viz., wisdom "which enables a man to regulate the more important modes of conduct in the more important affairs of life so as to achieve success in his career" (Mercier). By her intelligence she is able to gain a certain position, which through her lack of wisdom she is unable to retain. The instincts of sex, acquisition, and exhibition are uncontrolled, and result in sex immorality, fraud, and theft, in the wearing of her hair in a long false plait, and in her exalted impersonations. The maternal instinct is defective, the social instinct which should express itself in a desire for companionship, in consideration for and duty towards other members of the community, is undeveloped, the praise or blame of others, their approval or disapproval disregarded, altruism absent. the moral sense lacking. In these and in her failure in life are seen Jane's permanent mental defects, to these are due her anti-social career. That certain markedly anti-social lives are due to grudge formation or other mental conflict at an early age appears to be generally admitted, and one has known persistent criminal careers due to this cause. I was unable, however, to trace any such in my interviews with Jane. This was not surprising considering her ability for deception, and bearing in mind also the years which would have elapsed since such formation could have arisen; but I have been prompted to record her history, even at a time when the interpretation rather than the description of mental conditions is sought after, in view of the importance of moral imbecility and its admitted medico-legal difficulties. Some witnesses in court appear to rest their diagnosis on the turpitude of the particular offence with which the prisoner is charged, others to consider that all criminals are moral imbeciles, others again seem to hold the opposite view and to deny its existence apart from co-existing intelligence defect. The pitfalls are, however, lessened for that witness who only forms a diagnosis in conformity with the statutory definition.
It is usually only in such flagrant well-established cases as Jane's that the medico-legal witness is likely to obtain a sympathetic audience at the trial. It is when the unfolding of the case shows that the risk repeatedly run is out of proportion to the sought-for prize-the latter being neglected when obtainedthat the jury are likely to be persuaded that the crime is due to a mental defect.

\section{A CASE OF MELANOMA OF THE CHOROID.}

\section{BY A. E. KEOWN, M.B. BeLF.}

SARCoMATA, such as described in the following case usually originate near the optic disc and grow forward pushing the retina before them. I cannot find any account of choroidal melanomata not covered by retina or retinal vessels. This particular tumonr was seen in the first instance by Mr. Parry Morton, of Dowlais, an optician, who has supplied me with the following note :-

"W. T., an engine-driver, aged 62 , came to me complaining of discomfort in the left eye. On the nasal side behind the iris was an orange-coloured mass of the size of a lentil seed as seen by oblique focal illumination. It appeared to arise from the ciliary body or thereabouts. The fundus oculi and disc were normal. I warned the man that he had a most dangerous growth, that he must go at once to an ophthalmic surgeon, and refused to supply him with glasses."

This was in mid-August. Four weeks later he was seen by the present writer.

The whole pupil area was then occupied by a pale orangecoloured mass except a small space on the temporal side. There appeared to be a minute perforation of the sclerotic close to the corneal margin on the nasal side, evidently corresponding to the point of origin. The previous day he had seen Mr. Tudor Thomas, of Cardiff, who wrote that the tumour was a melanoma. Next day Mr. R. S. Mcclelland removed the eyeball in the Merthyr General Hospital, the patient at last consenting to the procedure as the sight of the eye was destroyed. All the conjunctiva and tissue near the perforation was removed, but the socket was not completely cleared as it was considered that the origin of the growth so far forward rendered so radical a procedure unnecessary.

The Clinical Research Association reported as follows :-

"The section shows a choroidal malignant growth which is a melanoma. The origin of the pigmented cells from one original pigmented layer of cuboidal cells is very well seen."

The division of the eyeball into two nearly equal halves shows beautifully the origin of the tumour by a narrow base from the retina free choroid between the ora serrata and the ciliary Diagram showing tumour pushing back

body. It did not hyaloid membrane. therefore neces-

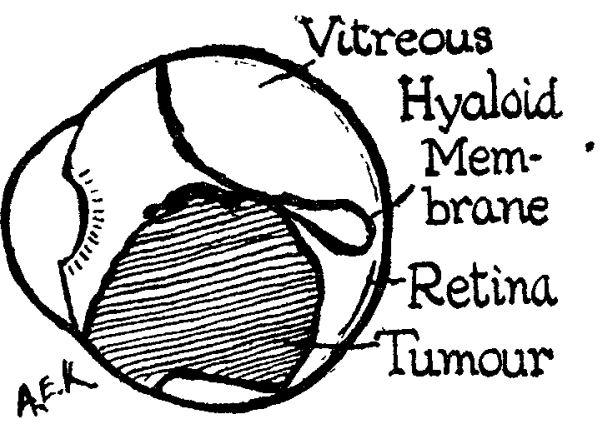

sarily cause retinal detachment, and it was not covered by retina. The growth bends back over the retina towards the disc pushing the hyaloid membrane in front of it. In Haab's Atlas a melanoma is figured with an anterior origin but lifting the retina. In our hemispheres the retina can be seen in normal position. The microscopic slide shows typical cells, many of which contain much melanin.

The patient works with a powerful electric arc light suspended on his left and he has complained very much of the glare. Te believes that the light had something to do with the causation of this trouble. The patient's opinion is of interest when one remembers the known effect of ultra-violet rays on the crystalline lens among men working in front of bright furnaces. The man is driving his stationary engine again. The stump is painless and can be rolled under the fingers. There is no enlargement of any abdominal viscus.

Dowlais, Glam. 


\section{Mtedital Socreties.}

\section{ROYAL SOCIETY OF MEDICINE.}

\section{SECTION OF NEUROLOGY.}

A MEETING of this section of the Royal society of Medicine was held on Nov. 10th, Mr. Percy Sargent, the President, being in the chair. Members of the Section of Surgery had been invited to attend. I discussion on

The Treatment of Persistent Pain due to Lesions of the Central and Peripheral Nervous Systems

was opened by Dr. WILFRED HARRIS, who said that persistent deep-seated pain, if accompanied by failing: health, would always suggest malignant disease. He considered the causes of pain in the peripheral nerveendings, and rapidly sketched the various forms of disease of the nerve trunks, posterior roots and their ganglia, the fillet or thalamus which gave rise to pain.

1. Peripheral Causes.-Dr. Harris said that neurofibrositis might be traumatic or rheumatic. The former had not been sufficiently recognised. He had once been consulted by a farmer for pain across the lumbar region, which had persisted with occasional acute exacerbations for 10 years, after a fall. Examination revealed a tender spot, and the patient was cured by the injection of a few drops of strong alcohol into this region. Lateral scoliosis might be associated with similar tender spots. Such neuro-fibrositis appeared to be due to inclusion of sensory nerveendings in areas of slight scarring resulting from rupture of muscle or tendon fibres, or as the result of a chill ; pain thus produced might occasionally persist for years until the nerve-ending was destroyed by strong alcohol. Trigeminal neuralgia was, he thought, probably due to septic neuritis of dental nerve filaments in the jaw. It was commoner in women than in men, on the right side than on the left, and in the upper jaw than in the lower. It was occasionally bilateral. In the early stages remissions commonly took place, but they became less frequent as the disease progressed. For the relief of this complaint drugs were useless, and the choice lay between alcohol injection of the Gasserian ganglion or of one of the main trunks, and operation (either gasserectomy or division of the sensory root of the fifth nerve behind the ganglion). Dr. Harris believed that alcohol injection of the ganglion produced as permanent a cure as the operation of gasserectomy. It had the advantage of being available for bilateral cases for which double gasserectomy was not permissible owing to the jaw-drop that would follow. Chronic non-paroxysmal neuralgia of either the upper or the lower jaw appeared to be limited to women usually of $15-35$ years of age. It might persist for years and differed from true "tic douloureux" in not being relieved unless total anæsthesia was produced, either by injection, neurectomy, or gasserectomy; whereas a light anæsthesia from partial injection of the nerve trunk was often sufficient in the latter complaint. Geniculate neuralgia sometimes followed facial palsy when accompanied by herpes of the auricle. Severe spasmodic pain in the neighbourhood of the auricle, the angle of the lower jaw, and the upper part of the neck might persist for weeks or months. American authors had described the cure of such cases by section of the "pars intermedia." Glossopharyngeal neuralgia was .very rare, but might simulate "tic douloureux" in the character and persistency of the spasms and pain. Sicard had reported section of the nerve behind the mandible as curing three cases.

2. Diseases of the Nerve Trunks.-Dr. Harris said that tumours at the base of the brain or naso-pharyngeal growths might simulate trigeminal neuralgia for a time, by irritation of the nerve, but the development of anæsthesia or motor palsy of the fifth nerve, or pressure symptoms such as diplopia or Eustachian deafness, would clear up the diagnosis. Gummatous neuritis of the fifth nerve might be recognised by persistent non-paroxysmal pain with the development of anosthesia, a positive Wassermann reaction, and rapid improvement under active anti-syphilitic treatment. The symptoms of cervical rib pressure, also far commoner in women, were often produced by a first thoracic rib, so that a negative skiagram would not exclude rib pressure. This was suggested by varying though persistent pain in the neck and along the inner side of the forearm with perhaps anæsthesia of the ulnar border of the forearm and wasting of the hand muscles. Causalgia was a common occurrence during the war, but very rare in civil practice. It was often due to very slight lesions of the nerve trunks, and could usually be relieved by free alcohol injection of the nerve trunk well above the site of injury.

3. Lesions of the Posterior Roots or their Ganglia.Post-herpetic neuralgia occurred mainly in patients over 50 years of age, and was confined to the region which had been involved in the herpes. Dr. Harris had recently had some success from alcohol injection in the Gasserian ganglion where the pain involved the first division of the trigeminal nerve. For post-herpetic neuralgia of spinal nerves posterior rhizotomy was not always successful. Hæmatorrhachis was an occasional cause of pain in the spinal nerve distribution. As regards the pain of tabetic crises he invited the experience of surgeons.

4. Central Sclerosis of the Fillel of Thalamus.Intramedullary growths and syringomyelia and syringobulbia occasionally caused pain; the posterior inferior cerebellar syndrome caused persistent trigeminal neuralgia.

5. Psychalgias. - These were legion. In many cases they might be recognised by their lack of anatomical distribution, but in some cases they were only recognised when treatment had failed to cure the supposed lesion. Dr. Harris gave two instances of this sort of pain.

\section{A Different Classification.}

Sir WILLIAM ThoRbURN referred to the difficulty in judging the effects of treatment of pain. There is no accurate means by which the degree of pain could be measured. The mental effect of prolonged pain often caused the recurrence of pain sometimes in another part, after the original pain had been cured. Thus Sir William Thorburn had recently seen two cases of pain due to cervical rib which had been cured by operation; the patients returned later complaining bitterly of abdominal pain associated with floating kidney. Sir William Thorburn divided cases into three classes: (1) those in which there was a definite lesion, such as pressure on the brachial plexus; (2) cases where the lesion was less definite and was possibly situated in the posterior root ganglia; (3) those in which there was no definite lesion and which he called neuralgia. In the first class the only question was diagnosis, and early diagnosis followed by prompt and adequate treatment was curative. In certain cases, however, where pressure had existed for a long time, a neuritis might be set up which caused pain even after removal of the original cause. This explained the failure in some cases of operation for cervical rib which had been too long postponed. In the second class of case Sir William Thorburn included certain cases of painful amputation stump. Some of these were cured by removal of end-bulbs, but a percentage of cases remained where pain persisted after removal of the bulb and several inches of apparently normal nerve. These cases were, he thought, due to an ascending neuritis, and in some of them posterior rhizotomy was the only resort. In his opinion these bulbs were due to sepsis, and did not occur if the nerves were cut sufficiently short.

As regards causalgia, resection and suture of the nerve was not always curative. Sixteen of his 20 